Andrews, R., Downe, J. \& Guarneros-Meza, V. (forthcoming). Contracting for Social Cohesion: Can Local Area Agreements Make A Difference. Policy \& Politics.

\title{
Contracting for Social Cohesion: Can Local Area Agreements Make
}

\section{a Difference?}

Dr Rhys Andrews (AndrewsR4@cardiff.ac.uk), $\operatorname{Dr}$ James Downe (DowneJ@cardiff.ac.uk) and Dr Valeria Guarneros-Meza (vgm@cardiff.ac.uk), Cardiff Business School

Summary. Under the Labour government, Local Strategic Partnerships (LSPs) in England were responsible for the delivery of Local Area Agreements (LAAs) agreed targets between central and local government. This paper uses statistical techniques and local authority case studies to explore the impact of LAAs on LSPS' efforts to promote social cohesion. The results suggest that LSPs with an LAA for social cohesion experienced a better rate of improvement in community cohesiveness than those without, and that tougher targets resulted in stronger improvement. The impact of changes in LSPs approaches to promoting social cohesion appears to be responsible for this finding.

\section{Key words}

Social cohesion; targets; partnership; local government; empirical analysis

Word count: 7,971 (incl. references and tables) 


\section{Introduction}

The cohesiveness of local communities has long been a central concern of social scientists (see Friedkin, 2004). More recently, it has become a key theme within public policy debates across the globe. Governments have sought to encourage local agencies to collaborate in order to deliver joined-up solutions to the challenges posed by increasing social diversity and anxieties about ethnic tensions (Marcuse, 1993; Beck and Beck-Gernsheim, 2002). In the UK, these developments were especially prominent during the 2000s. The Labour government of that time developed multiple policies to promote social cohesion (Lowndes and Thorp, 2011). One such policy instrument that was applied to the issue of social cohesion were Local Area Agreements (LAAs) - performance contracts between central government and the Local Strategic Partnerships (LSPs) held responsible for coordinating multi-agency approaches across local communities in England. About half of the LSPs (86) in England were subject to Local Area Agreements specifying targets for desired levels of social cohesion.

LAAs have recently been abolished by the Conservative-Liberal Democrat coalition government, but the role that such performance contracts might play in building cohesive communities remains of great interest. Concerns about social cohesion are highly evident across multiple levels of government in many European countries. The European Union (EU) too is deeply committed to promoting better approaches to managing demographic diversity in order to uphold social cohesion (European Commission, 2009). At the same time, the potential effectiveness of central initiatives to build social cohesion is of considerable salience, both across the EU (European Commission, 2011) and also within the UK, where an alternative doctrine of local freedom has now been embraced as the means to build the "big 
society" (Department for Communities and Local Government (CLG) 2010a). Finally, negotiated performance contracts remain an important tool within the apparatus of public sector management in many countries across the globe (Organization for Economic Co-operation and Development, 2005). This paper will therefore provide empirical evidence on the application of a negotiated performance management regime to a cross-cutting policy issue of high political salience.

Research on the role that local agencies can play in building social cohesion when working together has so far paid scant attention to the impact of target-setting, focusing rather on the coordination challenges posed by partnership working (Entwistle et al. 2007). At the same time, little attention has been paid to the efficacy (or otherwise) of LAAs (Gillanders and Ahmad 2007 for example, focus upon the early experiences of partner organizations involved in the formulation and implementation of LAAs). Indeed, to date, few empirical studies have systematically examined the relationship between targets and outcomes for local people more generally (for a notable exception, see Boyne and Chen's (2007) analysis of education achievements). Thus, despite the widespread debates about the merits of partnership and target-setting, important gaps remain in our understanding of the role that they can play in delivering improved outcomes for local people.

To explore the impact of LAAs on social cohesion, we use multivariate statistical techniques to examine the relationship between LAA targets per se and their relative "toughness" on the standard UK measure of social cohesion: residents' perceptions of the extent to which people from different backgrounds get on well. This analysis is then supplemented with qualitative evidence drawn from a sample of LSPs with highly divergent degrees of target toughness. In the first part of the paper, the policy context surrounding LSPs, LAAs and the issue of social cohesion is 
described. Next, theoretical perspectives on the relationship between targets and public service outcomes are explored to derive arguments about the likely effects of LAAs on social cohesion. Following this, measures of social cohesion, targets and target toughness are identified and described, as well as other variables which may impact on social cohesion. Statistical evidence on the impact of LAAs on residents' perceptions of social cohesion across the areas served by LSPs across England is then presented and set in the context of qualitative evidence on LSPs' work aimed at building community cohesion. Finally, the findings are analysed and the implications for future academic research and policy-making are discussed.

\section{Local Strategic Partnerships, Local Area Agreements and Social}

\section{Cohesion}

Broadly speaking, communities and societies are cohesive when aggregate level conditions 'are producing positive membership attitudes and behaviours' (Friedkin, 2004, p.410). The activities of local public agencies are likely to play an important role in building the potential for the production of such attitudes within any given area, though the means by which they seek to do this is likely to vary in line with the policy goals being pursued. For example, Lowndes and Thorp (2011) identify three modes of social cohesion existing in different localities across the UK. The first, the 'communitarian mode', is conceived in terms of shared values, aiming to build individuals' self-esteem and sense of belonging (2011: 519). The 'republican mode' places emphasis on political values and seeks cohesion through active citizenship, participation in local politics and inter-group communication (p.521). Finally, the focus of the 'neo-liberal mode' is on social inclusion, where cohesion is sought through economic means underpinned by security interventions (p.524). 
In the UK (and increasingly elsewhere), the so-called "crisis of social cohesion" prompted by the fragmentation of established identities in the wake of globalisation (Kearns and Forrest, 2000) led to the introduction of policies which made public organizations responsible for addressing the effects of this profound social change. Coupled with the turn to partnership working within the public sector, the fate of local communities became firmly tied to the development of joined-up governance arrangements across the multiple agencies present within local areas (Eurofound, 2006).

Theories of joined-up governance suggest that "wicked issues", such as the relative cohesiveness of local communities, are 'bigger than any single organization', so collaboration is necessary for 'making progress in alleviating the problem' (Raab and Milward, 2003: 414). Although individual agencies develop considerable expertise within their mandated area, wicked issues cut across or fall between these boundaries (Rittel and Weber, 1973). Thus, a 'multi-agency partnership response which harnesses the strengths and expertise of a variety of welfare perspectives' may have a better prospect of addressing intractable wicked issues (Milbourne et al., 2003: 19). To this end, the Labour government introduced a statutory requirement in England for representatives from the local statutory, voluntary, community and private sectors to come together in Local Strategic Partnerships (LSPs) to address local problems, allocate funding for cross-cutting projects, and agree on service delivery strategies.

LSPs were first established in 2000 with the intention of encouraging joint working, by breaking down the departmentalism and 'silo working' that prevented the most efficient allocation of resources to address the wicked issues confronting local communities. The structure of LSPs was determined at the local level, resulting in 
some variation in the composition, structure and processes of partnerships across England. Funding for the work of LSPs largely came from the statutory bodies (e.g. local authorities and primary care trusts) involved in them - though monies from specific initiatives, such as Neighbourhood Renewal Funding, could also be utilised. As LSPs evolved, so too did government policy on the role and responsibilities of the partnerships. In particular, LSPs became responsible for negotiating and implementing the Local Area Agreements (LAAs) - performance contracts between central government departments (represented by regional Government Offices in the negotiations) and each partnership - that replaced the Local Public Service Agreements (LPSAs) which set service improvement targets for local authorities.

Local Area Agreements were based on the idea that local public organizations can be incentivised to work together and improve outcomes by introducing performance contracts to focus their combined efforts. It meant that a range of organizations in an area (i.e in Bournemouth: the Council, Dorset Police, Bournemouth \& Poole Primary Care Trust and Prejudice Free Bournemouth \& Poole Group) were expected to join-up locally to try and address targeted indicators, such as local residents' perceptions of social cohesion within the area. Where LAAs represented a break from the LPSAs was that they 'focused on the delivery of outcomes for the area rather than the performance of individual institutions' (CLG, unpublished report: 1). This emphasis on wider area outcomes clearly marked out a new phase in the development of the Labour government's target regime, with the broader area-based focus allied with an area-based performance improvement regime (Comprehensive Area Assessment), inevitably requiring the involvement of multiple stakeholders. 
There was some unease about the LAA target approach from those working in local government. This stemmed partly from the view that this was another policy where local political leadership was being circumvented and also because there was not a shared vision about what LAAs aimed to do and where power lay in the process. Gillanders and Ahmad explained that 'Localities tended to see LAAs mainly as dialogue, central departments viewed them increasingly as contracts, and Government Offices were caught in the middle trying to satisfy both sides' (2007: 750). While the policy aimed to deliver better outcomes by improving co-ordination (ODPM 2004), stakeholders complained about having to deal with different government departments who were not joined up. Central government also placed pressure on LSPs to include certain issues (e.g. obesity) in a LAA where this was not necessarily a local priority.In theory, it was expected that LAA targets would help LSPs focus their strategic activity on wicked issues, such as social cohesion or youth unemployment. Within the context of this study, the LAA for social cohesion relied upon the setting of targets for improvements in the national indicator for social cohesion (NI1), which asked a representative sample of residents in each of the areas served by LSPs how well people from diverse backgrounds got on in that area. The development of targets for improvements on this indicator, presuppose that LSPs are able to coordinate the activities of a complex and multi-agency network of local and regional organisations, which can contribute to the sense of cohesiveness amongst the residents within the area that they serve. But why might the setting of such a target be expected to lead to subsequent improvements in social cohesion? 


\section{Target-setting and outcomes for local people}

The role of target-setting in the public sector is one of the most hotly debated and contested topics in public policy and administration (see Bevan and Hood, 2006) and was a key part of the New Labour government's modernisation agenda (Downe and Martin, 2008). Supporters of target-setting argue that it provides a clear sense of direction for organizations and can motivate people to focus extra attention on the pursuit of better outcomes (Capon et al, 1987). Indeed, theorists of the merits of goal clarity in public organizations emphasise that crystallising organizational aims into precise well-defined objectives is essential to ensuring that public managers can successfully negotiate the demands of myriad stakeholders without succumbing to the political pressures they exert (Chun and Rainey, 2005).

Critics of target-setting, however, argue that it restricts employees' innate sense of mission and may cause attention to be excessively focused upon the target that is being measured (Mintzberg, 1994), leading to a corresponding neglect of other important areas of organizational functioning (Wankhade, 2011). Moreover, narrowly defined goals can de-motivate staff who resent the imposition of expected levels of productivity. Quinn (1980), for example, suggests that vague organizational goals have a greater prospect of success because they can be interpreted and pursued in a multitude of different but equally valid ways - an argument that builds on Lindblom's classic (1959) arguments about the merits of "muddling through" in public sector organizations. The setting of targets, on this reading, may diminish professional autonomy by reducing the opportunity for staff to use their own discretion to set goals for public service provision. But what does existing empirical research tell us about the validity of these competing theoretical positions? 
Despite numerous trenchant critiques of the effects of target-setting offered by many scholars (e.g. Bevan and Hood 2006; Wankhade, 2011), to date, systematic empirical evidence supporting these arguments against targets has yet to emerge. Rodgers and Hunter's (1992) meta-analysis of 30 studies of management by objectives (MBOs - clear goal-setting and performance feedback) in public organizations finds that ' 100 percent of the public sector studies reported productivity or performance gain after the introduction of MBO' (1992: 33). Since that early review, a trickle of empirical studies has emerged that largely contribute further evidence on the merits of targets for public sector organizations.

The introduction of targets in the Flemish Employment Service is found by Verhoest (2005) to have prompted improved performance. Boyne and Chen's (2007) study of LPSAs and the school examination results of Local Education Authorities in England furnishes further support for the argument that the presence of targets is associated with service improvement. Likewise, Kelman and Friedman (2009) attribute shorter waiting times experienced by English NHS patients to the introduction of targets. Binderkrantz et al (2011) find that a larger proportion of production and project initiation goals within the performance contracts of Danish government agencies enhance goal attainment; though, Boyne and Gould-Williams (2003) study of Welsh local government managers indicates that performance may be negatively related to the sheer number of targets set. Although research on target-setting has yet to pay significant attention to cross-cutting outcomes for local people, such as social cohesion, it is, then, conceivable that targets may have benefits for these outcomes as well as for more tightly defined organizational goals. We therefore hypothesise that LSPs with an LAA for social cohesion will produce a 
better rate of improvement in levels of community cohesiveness than those without a target.

In addition to debating the merits of target-setting per se, public administration scholars have also discussed the extent to which the relative toughness or "stretch" in a target may have beneficial of harmful effects for outcomes (see Boyne and Chen, 2007). These debates were taken up by the Labour government, which sought to introduce elements of "stretch" into locally determined targets. The introduction of this stretch aspect was especially important for the performance contracts agreed with LSPs because each LSP starts from a different baseline. An easy target, so the theory goes, may be less likely to inspire or motivate managers to improve public services than a more challenging one. Studies of the determinants of individual motivation suggest that difficult but achievable targets are associated with greater

effort and achievement (e.g. Latham et al, 2008; Walker and Boyne 2006). Thus, outcomes for local people may be more likely to be boosted if LAAs "stretch" LSPs to improve beyond their existing level of achievement. This leads to the hypothesis that LSPs with tougher social cohesion LAAs will improve the most.

\section{Data and measures}

The units of analysis for our study are the areas served by Local Strategic Partnerships in England (i.e. the 150 jurisdictions that were served by single and upper-tier local authorities). Eighty-six of these partnerships were subject to Local Area Agreements specifying targets for desired levels of social cohesion. As such, the areas served by LSPs are a particularly suitable context for investigating the potential impact of target-setting on social cohesion. In addition to the introduction of LAAs for social cohesion, broad concerns about a 'civic deficit' in the UK led the 
Labour government to introduce a slew of initiatives to support and promote community development in the areas served by local authorities (see Andrews et al 2008). At the same time, this focus on the local as the source of social cohesion is continuing under the coalition government; albeit with a much less state-centric emphasis (Sullivan, 2012).

\section{Dependent variable}

For this study, social cohesion is measured as an attitudinal phenomenon reflecting individuals' perceptions of the cohesiveness of their local community (see Moody and White, 2003). Quantitative data on citizens' perceptions of social cohesion within the areas served by LSPs are drawn from the General User Survey conducted by local authorities across England in 2006 and the Place Survey carried out in 2008. Both surveys asked a representative sample of residents a series of questions about the quality of life in their local area. Data were independently verified by the Audit Commission. Each local authority was required to achieve a sample size of 1,100 based on a confidence interval of $+/-3 \%$ at the $95 \%$ confidence level.

The questions within the General User and Place Surveys were all based on a 5-point response scale with the published figures showing those agreeing with the survey statements as a percentage of those responding to the question (see CLG, 2007; 2008). An item assessing whether respondents believed that people from diverse backgrounds got on well together in the area was included in both surveys specifically to gauge perceived levels of social cohesion. This question became the standard survey item used by the Labour government as an indicator of a cohesive society. It captures the overall degree of harmony between groupings based on 
social class and economic position, as well as those based on faith or ethnic identities (CLG, 2008).

To gauge the extent to which the introduction of an LAA for social cohesion led to improvements in cohesiveness, a rate of improvement measure was constructed by calculating the percentage change in the rate of cohesion between 2006 and 2008. Thus, the statistical modelling provides an indication of how much difference the independent and control variables made to changes in perceived social cohesion during the time that LAAs were introduced.

\section{Independent variables}

To assess the effects of an LAA for social cohesion, dichotomous variables are created coding LSPs with a LAA for social cohesion 1 (target on) and all the others 0 (target off). The degree of LAA stretch is then measured using a dichotomous variable that codes the rate of improvement required to achieve an LAA based on perceptions of cohesion in the year prior to introduction of the LAA (i.e. the indicator score in 2006), and coded zero if no LAA is present. Missing data mean that the target stretch analysis is carried out on a slightly smaller sample of cases.

\section{Control variables}

Socio-economic disadvantage. The relative socio-economic disadvantage of citizens was measured using the average ward score on the indices of deprivation for each of the areas served by an LSP in 2007. Communities experiencing socio-economic disadvantage arguably lack the resources to solve collective action problems (Kornhauser, 1978), have high levels of crime and disorder (Kawachi, Kennedy \& Wilkinson, 1999), and thereby correspondingly lower levels of cohesiveness. 
Demographic diversity. The sheer number of alternative social identities in demographically diverse areas may problematise efforts to enhance cohesion. For example, ethnically diverse areas may suffer from low levels of social trust (Alesina \& La Ferrara, 2002), areas with a wide spread of age groups greater generational conflict (Withers, 1997), and those with high social class diversity, confrontation between different sectional interests (Costa \& Kahn, 2003). To measure demographic diversity, the proportions of the age, ethnic and social class sub-groups identified in the 2001 UK national census (e.g. children aged 0-4, Black African and Lower Managerial and Professional Occupations), for each LSP area were squared, summed and subtracted from 10,000, with a high score reflecting high diversity.

Social alienation. Population size and density figures for 2001 control for the possibility that residents of bigger, more densely populated urban areas experience higher levels of social alienation and disaffection (Oliver, 2000). Moreover, cities with dense populations may offer greater opportunities for criminal and delinquent behaviour to flourish (Kposowa et al 1995), in turn, damaging perceptions of cohesiveness.

Government resources To develop and empirically test for the impact of LAAs, it is also necessary to control for the distribution of government resources to promote social cohesion within the areas served by LSPs. Thus, a measure of the neighbourhood renewal funding per capita allocated by UK central government is included in the models to control for the financial resources made available to LSPs 
to produce better social and economic outcomes in disadvantaged areas (Social Exclusion Unit, 2001).

Local government structure To control for differences between type of LSP area within the analysis three dichotomous variables are created: a) coding 1 for county council areas and all other areas; b) coding 1 for London borough areas and all other areas; c) coding 1 for metropolitan borough areas and all other areas. Unitary authority areas are the reference category.

Table 1 presents the descriptive statistics for the independent and control variables used in the modelling of social cohesion. Logged versions of population and population density were used in the analysis.

[Table 1 Here]

\section{Statistical findings}

Results for statistical tests of the relationship between LAAs and the rate of improvement in social cohesion across the areas served by LSPs are shown in Table 2. Three Ordinary Least Squares Regression (OLS) models are presented: model 1 regresses the control variables on to the rate of improvement in social cohesion. The results when the 'target on' dummy variable is included in the equation are shown in model 2. Finally, model 3 substitutes the target stretch variable for the 'target on' measure.

[Table 2 Here] 
The statistical results provide virtually no support for the proposed relationships between the control variables and the rate of improvement in social cohesion. Although the signs for the coefficients are mostly in the expected directions, only the variable controlling for whether or not an LSP operates within a metropolitan borough is statistically significant. Part of the reason for the absence of statistically significant relationships here is that by taking the rate of improvement as the dependent variable we effectively control for the impact of past levels of social cohesion on present levels. Indeed, when one examines the effects of the control variables on raw levels of cohesion in both 2006 and 2008, numerous statistically significant relationships emerge. At the same time though, the finding on the challenges faced by LSPs seeking to improve social cohesion in metropolitan boroughs is an intriguing one. These areas are located in large Northern and Midland urban conurbations where racial tensions were particularly high during the early 2000s (Webster 2003). Indeed, it was a series of race riots in Bradford, Burnley and Oldham which prompted the emergence of social cohesion as a key policy goal of the Labour government (Hudson et al. 2007). This finding may therefore mirror other evidence, which underscores the difficulties that a legacy of ethnic tension poses for social cohesion in urban areas (e.g. Uitermark et al. 2005).

Despite the moderate statistical power of the first model, the introduction of the 'target on' measure provides some support for the argument that the introduction of an LAA for social cohesion will result in improved outcomes for local people. The coefficient for the 'target on' measure is positive and statistically significant and its inclusion in the regression model makes a small statistically significant addition to the explanatory power of the regression model of about two per cent. In a survey of LAA co-ordinators, $90 \%$ of the respondents agreed that an outcomes framework 
based on negotiated and shared targets was a useful lever in delivering the LAA (and $60 \%$ thought that the National Indicator Set was useful). And over three quarters of respondents thought a duty on identified partners to have regard to specific targets in the LAA brought more change than would otherwise have been the case (CLG, 2010b). The size of the coefficient for the 'target on' measure in our statistical model suggests that LSPs with an LAA for social cohesion have been able to improve (or reduce deteriorations in) perceptions of social cohesion by almost a whole percentage point more (0.95) than those without an LAA. Although substantively this effect size is comparatively small, the third model presented in Table 2 indicates that the degree of stretch in the target exerts a much greater impact on the rate of improvement in social cohesion.

The target stretch measure makes a large statistically significant addition to the explanatory power of the regression model of about 35 per cent. Substantively, the size of the coefficient for the stretch measure suggests that for every percentage point increase in target toughness, there is a corresponding .65 per cent improvement in perceptions of social cohesion in those local areas served by LSPS with a social cohesion LAA. This is clearly a very sizeable effect size and one that points towards strong target stretch benefits. In fact, an unpublished report concludes that, 'the prime benefit of LAAs was that they provided the impetus to joint working on priorities especially where there were particular challenges' (CLG, 2010b: 30).

There are a number of potential ways in which contracting for cohesion at the local level might lead to enhanced joint-working. Firstly, it is conceivable that LSPs with more stretch in their social cohesion LAAs are working harder and better to improve residents' perceptions of their local community than those with less stretch 
in their LAA, especially by investing more in community development and public participatory activities. Previous research suggests such work can positively influence cohesiveness (Andrews et al 2011). At the same time, LSPs pressurised to meet tough cohesion targets may well have carried out publicity and advertising campaigns. Prior studies have suggested that public attitudes towards government can be altered through the use of simple, cost-effective marketing strategies (Berman, 1997; Ipsos-MORI 2006). To explore the potential causal mechanisms at work here we draw upon qualitative data on the work of those LSPs with the 'toughest' and 'easiest' targets in promoting social cohesion.

\section{LAAs as drivers of change}

One of the principal reasons the five LSPs with the toughest social cohesion targets (Barking and Dagenham, Newham, Bournemouth, Southend and Peterborough) cited for negotiating a tough LAA was the impetus such a target would give to work aimed at responding to community tensions around the issue of immigration. In Barking and Dagenham, the British National Party (BNP) formed the largest opposition party on the council between 2006 and 2010, and community tension was placed on the council's risk register. In Newham, the LSP regarded the cohesion LAA as an excellent opportunity to institute a new coordinated approach to dealing with the large numbers of undocumented immigrants in the borough (Newham, 2007). In Bournemouth and Peterborough, the integration of the large number of Central and Eastern European migrant workers living within the area was identified as a major priority for the LSPs (Dorset Race Equality Council, 2010; Peterborough, 2006), while in Southend, increased BNP activity coupled with rising levels of immigration brought local agencies together (Barber, 2010). 
The agreement of stretching LAAs for social cohesion led each of the above LSPs to carry out extensive new activities to improve their performance on this measure. This work tended to be 'communitarian' based around efforts to engage with civil society and voluntary sector organizations to build shared values within the community (Lowndes and Thorp, 2011), though there was also evidence of initiatives with a more consumerist 'neo-liberal' orientation.

\section{Community development activities}

In Barking and Dagenham, new funding was provided for the Volunteer Bureau and the 'Giving Back' awards during Peace Week. Alongside the introduction of new events like the Rising Star awards for young people, guidance was also produced for schools and governors on promoting shared values, and the Faith Forum commissioned to drive inter-faith work in the area. In Newham, the Council (along with partners) introduced events such as the Mayor's Newham Show and smaller Community Forums. In addition, Active Community Teams made up of volunteers working with local councillors were set up in nine areas to hold free events and identify local priorities.

In Bournemouth, the LSP developed a series of 'bridging' projects, such as multi-cultural days and sport activities to celebrate the values of different immigrant communities. In Southend, the work of the Association of Voluntary Services was expanded to empower local people to have a greater voice and role in provision of local services. In addition to coordinating the Ethnic Minority Forum and the Polish Surgeries and Festival in the area, three other activities involving the LSP stand out. The Turning Tides initiative that brought together statutory, private and voluntary sector organisations to address local priorities, the Active Citizens programme that 
supported residents to build neighbourhood improvement networks, and the multisectoral programme Citizen Power, which sought to generate 'sustainable citizenship' through the medium of art events.

\section{Marketing and communication campaigns}

Barking and Dagenham LSP published a Community Cohesion strategy in 2007, and the local authority now routinely considers community cohesion impacts when designing new policies. It has also significantly expanded representation on the borough's Tension Monitoring Group and provides a Welcome Pack to anyone moving into the borough. Moreover, the local authority was commended by central government for its innovative work addressing urban myths (e.g. 'Africans are being paid to come to Barking and Dagenham' or that public services disproportionately favour black minority ethnic residents).

In Bournemouth, the LSP developed new initiatives to reduce prejudice and discrimination and improve confidence to report hate crime, such as appointing a Community Cohesion Officer and forming a Prejudice Free Bournemouth and Poole Group. A County-wide publicity campaign was also instituted to highlight reporting of racist/homophobic incidents. In Peterborough, in addition to the introduction of a migrant English language skills and knowledge programme, the New Link community service was set up to help newcomers integrate by advertising training and job opportunities, and informing them about the legal requirements of living in Britain and volunteering roles. 


\section{LAAs as drivers of consolidation}

The context in the five LSPs with the least stretch in their cohesion LAA was not radically dissimilar to that in those LSPs with the most stretch in their LAA. Camden, Rochdale, Sandwell and Knowsley all contain wards with high levels of deprivation, some of which have experienced significant racial tensions, and others of which have seen the BNP become more visible. In East Sussex, the LAA was centred on work going on in Hastings Borough Council to address tensions associated with the presence of large numbers of immigrants and asylum seekers within that particular area. It is not, therefore, in the contextual circumstances that the different outcomes for more and less challenging LAAs can be found.

There are a number of different reasons why authorities may have set 'soft' targets. In some cases, there may have been some complacency. In Knowsley, for example, the black and minority ethnic population represents less than $2 \%$ of the population and no community cohesion strategy was in place until 2009. At the same time, there were also disagreements between some of these LSPs and the government about the measurement of NI1, with the LSPs subscribing to lower baseline figures (which would actually render their targets somewhat tougher). Nevertheless, since substitution of the LSPs preferred figures for those published by CLG did not alter the statistical results that we observe, we focus our attention on the possibility that the target stretch effect has its roots in alternative approaches toward (and histories of) community engagement.

A common theme running through the negotiation of the less demanding cohesion targets, however, was the desire to consolidate existing local authority practices in building a cohesive community. The strength of the institutional legacy of public participation work within those LSPs with less challenging LAAs is especially 
striking, being suggestive of a more 'republican' approach that relies upon political means to strengthen community cohesion (Lownes and Thorp, 2011). For example, Camden council has a track record of civic engagement demonstrated by its longterm commitment to a Community Cohesion Working Group (including politicians from the three major political parties) and strategies that invite community members to work jointly with the organization. Likewise, Rochdale has a strong history of working with local communities through various public participatory fora (CLG, 2006), and Sandwell, too, has well-established practices for engaging with the many diverse ethnic communities within the area and involving them in local decision-making. In Knowsley, community development activity was scaled-up to become more participatory through the use of Objective one funding in the late 1990s (Hibbitt et al, 2001). Hastings was one of the pioneers of comprehensive community planning (http://www.communityplanning.net/toolkits/UrbanGovToolkitsCPH.pdf)

The 'republican' approach to promoting social cohesion focuses on the pursuit of political consensus (Lowndes and Thorp, 2011), and it may be that in areas with a stronger participative political culture there is less need to challenge local public service providers to work more closely with civil society groups as this already wellembedded. The new (or greatly increased) commitment to a 'communitarian' approach to cohesion within LSPs with the most stretch in their LAA may therefore be just the first step towards the eventual development of the kind of institutional structures that can facilitate a republican civic culture. The relative contribution of the 'communitarian' and 'republican' (and 'neo-liberal') approaches to improvements in perceptions of social cohesion is thus a question that merits extended consideration in subsequent research. 


\section{Conclusion}

This paper has explored the role that performance contracts can play in building social cohesion by analysing whether LAAs spurred improvements in perceptions of cohesiveness across the areas served by LSPs in England. The statistical results suggest that the rate of improvement in citizens' perceptions of cohesion is positively associated with the introduction of a social cohesion LAA. Nevertheless, the benefits of such target-setting emerge most strongly where there is greater stretch in the agreed target. To further explore our findings, we drew upon case study material, which suggests that LSPs supported both community development activites and publicity actions and campaigns in their attempt to positively influence residents' perceptions of cohesion. Although the analysis of the qualitative data did not track in detail the actions "on the ground" to improve coordination across service areas and organizations, the community cohesion initiatives of LSPs appears likely to be an important influence on local outcomes. Our case studies suggest that the introduction of tough LAAs for social cohesion may have been an important motivation behind an expansion of community development work in LSPs. For those LSPs with less challenging targets, the LAA seems to have reinforced the good practice already underway in the locality.

The findings from our study have wider international relevance, particularly given the vogue for public sector partnership arrangements (Entiwistle, 2010) and the rise of management by targets in many countries (Heinrich and Marschke, 2010). Our research indicates that negotiated performance contracts may be an important policy tool for national and local policy-makers seeking to improve outcomes for local communities. Furthermore, the considerable challenges associated with ensuring that joined-up governance works for local people appear (at least partially) to be 
susceptible to the application of state-sponsored interventions. Indeed, the evidence we present seems to indicate that performance contracts with tough targets for improving outcomes may be an especially effective way of making agencies responsible for dealing with wicked problems work together. Even so, it is clear that there are significant challenges to be overcome in the negotiation of performance contracts between central and local governments, both in terms of agreeing upon an actual target in the first place, and upon the reliability of the measures used to evaluate achievement of that target thereafter,

The amount of time and effort devoted to target negotiation underlines that there may be an incentive to 'game' the system, and that agencies may become too narrowly focused on hitting targets at the expense of other important activities something we were unable to study systematically on this occasion. Nevertheless, our case study evidence also indicates that performance contracts can be responsible for significant positive changes in the behaviour of public agencies. Of course, the areas in which the toughest targets were set face very distinctive circumstances, but new social needs and political challenges have arisen as a consequence of rapid economic and demographic change all across Europe (see Council of Europe, 2007). The experiences of English LSPs with social cohesion LAAs may therefore offer valuable lessons for policy-makers elsewhere.

The coalition government's decision to abolish the LAA model is an indicator both of their claim to support the principles of 'localism' but also of their ideological desire to place responsibility for local budget setting at the local government level. It is ironic, however, that while LAAs aimed at simplifying central government funding, joining-up public services more effectively and targeting funding towards local priorities, the rhetoric surrounding its' abolition has been couched in similar terms. 
The Minister announced that 'the abolition of centrally driven targets... will instantly remove reporting on 4,700 Whitehall targets from councils' daily workloads. Instead, local areas will be in control of their own delivery targets, answering to residents' (Pickles, 14/10/10). It is too early to conclude what impact this move toward a more localist stance will have on improving outcomes for citizens.

Despite the strength of the findings, the analysis presented here has limitations. In particular, longitudinal studies using quantitative and qualitative data could further illuminate the effects of target-setting. Unfortunately, it is not possible to extend the data set we have to track these accurately, because both LAAs and the Place Survey on which the measurement of social cohesion depends have been abolished. Nevertheless, while the coalition government have removed Labour's emphasis on top-down performance management, there is evidence to suggest that LSPs and other partnership bodies are continuing to operate performance management frameworks which collate together data on outcomes and objectives set out in sustainable community strategies and other plans. The difference is that now reporting and accountability is sideways to partner organizations and downwards to citizens rather than upwards to central government. By drawing on other long-standing indicators of cohesion in local areas, such as crime rates, community organizational life and electoral participation and marginality, it may still be possible to gain an insight into the merits of locally versus nationally negotiated performance contracts.

\section{Acknowledgements}

The research leading to these results has received funding from the European Union's Seventh Framework Programme under grant agreement No. 266887 
(Project COCOPS), Socio-economic Sciences \& Humanities. Data collected for research funded by the Department for Communities and Local Government is also incorporated within the paper. The views expressed are however those of the authors and do not necessarily represent those of the Department.

\section{References}

Alesina, A., and La Ferrara, E. (2002) 'Who trusts others?', Journal of Public Economics, vol 85, no 2: 207-34.

Andrews, R., Cowell, R.J. and Downe, J. (2008) 'Support for active citizenship and public service performance: an empirical analysis of English local authorities', Policy \& Politics, vol 36, no 2: 225-44.

Andrews, R., Cowell, R.J. and Downe, J. (2011) 'Promoting civic culture by supporting citizenship: what difference can local government make?', Public Administration, vol 89, no 2: 595-610.

Armstrong, H. and Taylor, J. (2000) Regional economics and policy, $3^{\text {rd }}$ edition, Oxford: Blackwell.

Barber, J. (2010) Missing communities - the final report. Southend: SouthendCommunity-in-Harmony Partnership.

Beck, U. and Beck-Gernsheim, E. (2002) Individualization. institutionalized individualism and its social and political consequences. London: Sage Publications.

Berman, E.M. (1997) 'Dealing with Cynical Citizens', Public Administration Review, vol 57, no 2: 105-12. 
Bevan, G. and Hood, C. (2006) 'What's measured is what matters: targets and gaming in the English public health care system', Public Administration, vol 84, no 3: 517-38.

Binderkrantz, A.S., Holm, M. and Korsager, K. (2011) 'Performance Contracts and Goal Attainment in Government Agencies', International Public Management Journal, vol 14, no 4: 445-63.

Boyne, G. and Chen, A. (2007) 'Performance targets and public service improvement', Journal of Public Administration Research and Theory, vol 17, no 3, 455-77.

Boyne, G. and Gould-Williams, J. (2003) 'Planning and performance in public organizations: an empirical analysis', Public Management Review, vol 5: 115-32.

Capon, N., Farley, J. and Hulbert, J. (1987) Corporate strategic lanning. New York: Columbia University Press.

Cheong, P.H., Edwards, R., Goulbourne, H. and Solomos, J. (2007) 'Immigration, social cohesion and social capital: A critical review', Critical Social Policy, vol 27: 24-49.

Chun, Y.H. and Rainey, H.G. (2005) 'Goal ambiguity in US federal agencies', Journal of Public Administration Research and Theory, vol 15: 1-30.

Commission on Integration and Cohesion (2007). Our shared future. London: HMSO.

Costa, D.L. and Kahn, M.E. (2003) 'Understanding the American decline in social capital, 1952-1998', Kyklos, vol 56, no 1: 17-46.

Council of Europe (2007) Report of the high-level task force on social cohesion in the $21^{\text {st }}$ Century: Towards an active, fair and socially cohesive Europe. Strasbourg. 
Department for Communities and Local Government (CLG) (2006) Supporting Effective Citizenship at a Local Level. Office of the Deputy Prime Minister: London.

CLG (2007b) Best value user satisfaction surveys 2006-07. Department for Communities and Local Government: London.

CLG (2008) Communities in control: real people and real power. London: HMSO.

CLG (2010a) Draft Communities and Local Government Structural Reform Plan. London: DCLG.

CLG (2010b) Report on the 2009 survey of all English Local Area Agreements: longterm evaluation of local area agreements and local strategic partnerships. London: DCLG.

CLG. Long-term evaluation of local area agreements and local strategic partnerships, Final report. unpublished.

Dorset Race Equality Council (2010) 'What are the needs of migrant workers in relation to accessing public services in Bournemouth and Poole?', Report of the Migrant Support Project. Bournemouth: DREC.

Downe, J. and Martin, S. (2008) 'Evaluating the Local Government Modernisation Agenda: impacts, obstacles and outcomes', Local Government Studies, vol 34, no 1: 105-7.

Entwistle, T. (2010) 'Collaboration', in: R. Ashworth, G.A. Boyne and T. Entwistle (eds), Public Service Improvement: Theories and Evidence, Oxford: Oxford University Press..

Entwistle, T., Bristow, G., Hines, F., Donaldson, S. and Martin, S. (2007) 'The dysfunctions of markets, hierarchies and networks in the meta-governance of partnership', Urban Studies, vol 44, no 1: 63-79. 
European Commission (2009) Sixth progress report on economic and social cohesion. Brussels: CEC.

European Commission (2011) Pluralism and religious diversity, social cohesion and integration in Europe. Brussels: Directorate-General for Research and Innovation. Eurofound (2006) Local partnership: a successful strategy for social cohesion? Dublin: Eurofound.

Friedkin, N.E. (2004) 'Social cohesion', Annual Review of Sociology, vol 30: 409-25.

Gillanders, G. and Ahmad, S. (2007) 'Win-win? Early experience from Local Area Agreements', Local Government Studies, vol 33, no 5: 743-60.

Heinrich, C.J. and Marschke, G. (2010) 'Incentives and their dynamics in public sector performance management systems', Journal of Policy Analysis and Management, vol 29, no 1: 183-208.

Hibbitt, K. Jones, P. and Meegan, R. (2001) Tackling social exclusion: The role of social capital in urban regeneration on Merseyside - from mistrust to trust? European Planning Studies, vol 9, no 2: 141-61.

Hudson, M., Phillips, J. Ray, K. and Barnes, H. (2007) Social cohesion in diverse communities, York: Joseph Rowntree Foundation.

Ipsos-MORI (2006) The business case for the reputation project. London, IpsosMORI.

Kawachi, I., Kennedy, B.P., and Wilkinson, R. (1999) 'Crime: social disorganization and relative deprivation', Social Science and Medicine, vol 48, no 6: 719-31.

Kearns, A. and Forrest, R. (2000) 'Social cohesion and multilevel urban governance', Urban Studies, vol 37, nos (5-6): 995-1017.

Kelman, S. and Friedman, J.N. (2009) 'Performance improvement and performance dysfunction: An empirical examination of distortionary impacts of the emergency 
room wait-time target in the English National Health Service', Journal of Public Administration Research and Theory, vol 19, no 4: 917-46.

Kornhauser, R. (1978) Social sources of delinquency. Chicago, IL: University of Chicago Press.

Kposowa, A.J., Breault, K D. and Harrison, B.M. (1995) 'Reassessing the structural covariates of violent and property crimes in the USA - a county level analysis', British Journal of Sociology, vol 46, no 1: 79-105.

Lindblom, C. (1959) 'The science of muddling through', Public Administration Review, vol 19: 79-88.

Latham, G.P., Borgogni, L. and Petita, L. (2008) 'Goal setting and performance management in the public sector', International Public Management Journal, vol 11, no 4: 385-403.

Lowndes, V. and Thorp, L. (2011) 'Interpreting ‘community cohesion': modes, means and mixes', Policy \& Politics, vol 39, no 4: 513-32.

Marcuse, P. 1993. 'What's so new about divided cities?', International Journal of Urban and Regional Research, vol 17: 355-65.

Milbourne, L., Macrae, S. and Maguire, M. (2003) Collaborative solutions or new policy problems: Exploring multi-agency partnerships in education and health work. Journal of Education Policy, vol 18, no 1: 19-35.

Mintzberg, H. (1994) The rise and fall of strategic planning. London: Prentice-Hall. Moody, J. and White, D.R. (2003) 'Social cohesion and embeddedness: A hierarchical conception of social groups', American Sociological Review, vol 68, no 1: 103-27.

Newham Borough Council (2007) 'Local Area Agreement 2007-2010: Parts A \& C'. 
ODPM (Office of the Deputy Prime Minister) (2004) Local Area Agreements: A Prospectus. London: ODPM

Oliver, J.E. (2000) 'City size and civic involvement in metropolitan America', American Political Science Review, vol 94, no 2: 361-74.

Organization for Economic Co-operation and Development (2005) Modernising government: the way forward. Paris: OECD.

Peterborough City Council (2006) Growing the Right Way. Peterborough's Local Area Agreement.

Pickles, E. (2010) Councils' red tape cut as 4,700 Whitehall targets slashed https://www.gov.uk/government/news/councils-red-tape-cut-as-4-700-whitehall$\underline{\text { targets-slashed }}$

Quinn, J. (1980) Strategies for change: logical incrementalism. Homewood, Illinois: Richard D. Irwin.

Raab, J. and Milward, H.B. (2003) 'Dark networks as problems', Journal of Public Administration Research and Theory, vol 13, no 4: 413-39.

Rittel, H.W.J. and Webber, M.M. (1973) 'Dilemmas in a general theory of planning', Policy Sciences, vol 4: 135-69.

Rodgers, R. and Hunter, J.E. (1992) 'A foundation of good management practice in government: Management by Objectives', Public Administration Review, vol 52: 27-39.

Social Exclusion Unit (2001) A new commitment to neighbourhood renewal: National strategy action plan. London: Cabinet Office.

Stunell, A. (2010) 'Keeping faith in the Big Society", speech by Parliamentary UnderSecretary in the Department of Communities and Local Government to The InterFaith Network for the UK, $12^{\text {th }}$ July 2010. 
Sullivan, H. (2012) 'The big society needs an active state', Policy \& Politics, vol 40, no 1: $145-8$.

Uitermark, J., Rossi, U. and Van Houtum, H. (2005) 'Reinventing multiculturalism: urban citizenship and the negotiation of ethnic diversity in Amsterdam', International Journal of Urban and Regional Research, vol 29, no 3: 622-40.

Verhoest, K. (2005) 'Effects of autonomy, performance contracting, and competition on the performance of a public agency: a case study', Policy Studies Journal, vol 33, no 2: 235-58.

Walker, R.M. and Boyne, G.A. (2006) ‘Public management reform and organizational performance: an empirical assessment of the UK Labour government's public service improvement strategy', Journal of Policy Analysis and Management, vol 25, no 2: 371-93.

Wankhade, P. (2011) 'Performance measurement and the UK emergency ambulance service: unintended consequences of the ambulance response time targets', International Journal of Public Sector Management, vol 24, no 5, 384402.

Webster, C. (2003) 'Race, space and fear: imagined geographies of racism, crime, violence and disorder in Northern England', Capital and Class, vol 27, no 2, 95122.

Withers, S.D. (1997) 'Demographic polarization of housing affordability in situ major United States metropolitan areas', Urban Geography, vol 18, no 4: 296-323. 
Table 1 Descriptive statistics

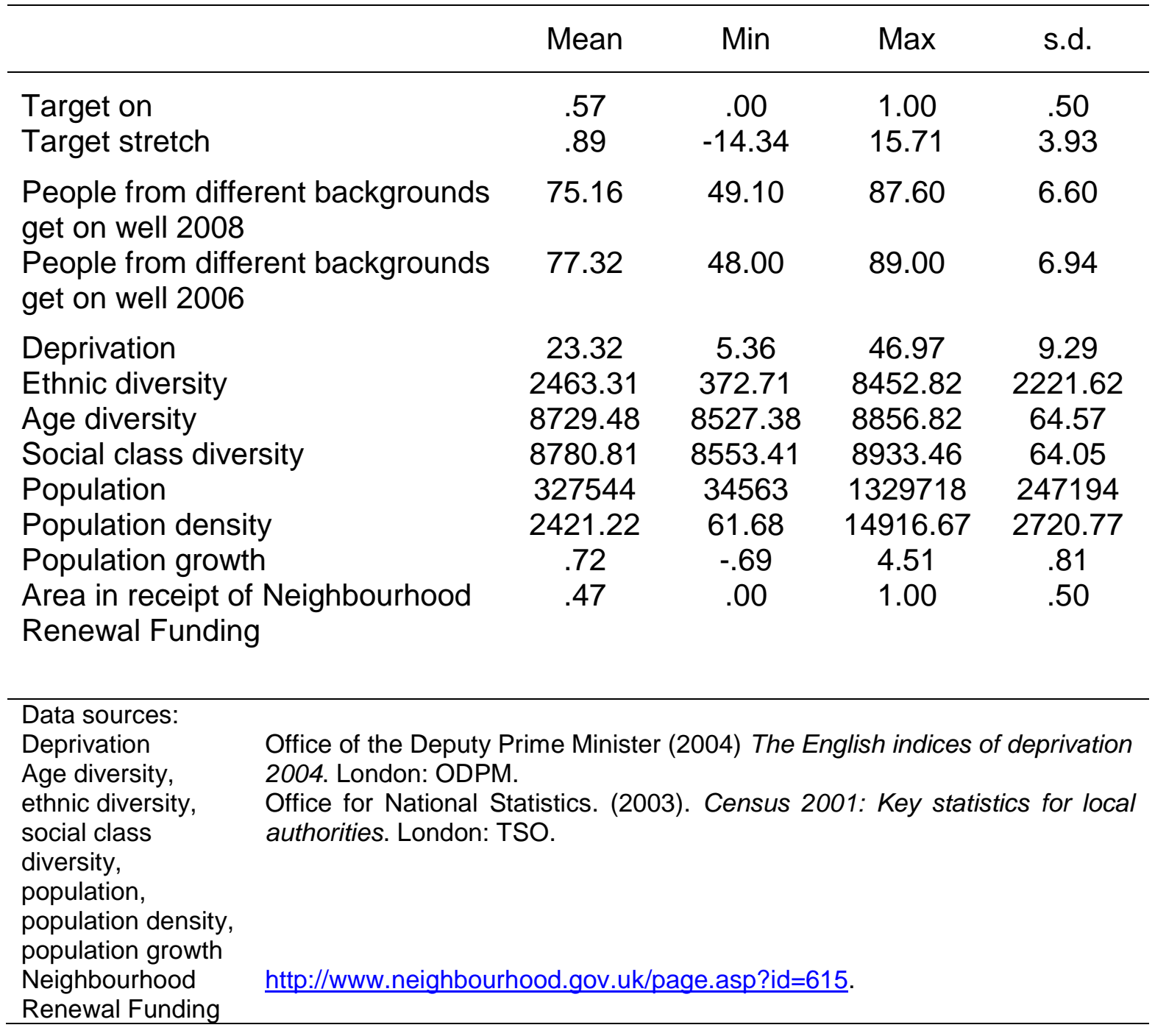




\begin{tabular}{|c|c|c|c|c|c|c|}
\hline & \multicolumn{2}{|c|}{ Model 1} & \multicolumn{2}{|c|}{ Model 2} & \multicolumn{2}{|c|}{ Model 3} \\
\hline & Slope & Robust s.e. & Slope & Robust s.e. & Slope & Robust s.e. \\
\hline $\begin{array}{l}\text { LAA (target on) } \\
\text { LAA (target stretch) }\end{array}$ & & & $.952+$ & .659 & $.651^{* *}$ & .090 \\
\hline $\begin{array}{l}\text { Control variables } \\
\text { Deprivation } \\
\text { Age diversity } \\
\text { Ethnic diversity } \\
\text { Social class diversity } \\
\text { Population (log) } \\
\text { Population density (log) } \\
\text { Population growth } \\
\text { NRF area } \\
\text { London borough } \\
\text { Metropolitan borough } \\
\text { County council }\end{array}$ & $\begin{array}{l}-.032 \\
.001 \\
-.0001 \\
-.006 \\
-.114 \\
-.151 \\
-.221 \\
-.281 \\
-.258 \\
-2.481^{\star *} \\
-1.059\end{array}$ & $\begin{array}{l}.065 \\
.006 \\
.0004 \\
.006 \\
.669 \\
.526 \\
.363 \\
1.224 \\
1.497 \\
1.055 \\
1.269\end{array}$ & $\begin{array}{l}-.043 \\
-.0004 \\
-.0002 \\
-.007 \\
-.009 \\
-.094 \\
-.203 \\
-.167 \\
-.404 \\
-2.702^{\star *} \\
-1.299\end{array}$ & $\begin{array}{l}.066 \\
.006 \\
.0004 \\
.007 \\
.650 \\
.504 \\
.362 \\
1.215 \\
1.473 \\
1.092 \\
1.223\end{array}$ & $\begin{array}{l}-.007 \\
-.002 \\
.0001 \\
-.012^{\star} \\
.980^{\star} \\
-.157 \\
.193 \\
.465 \\
-1.387^{\star} \\
-1.802^{\star} \\
-1.144\end{array}$ & $\begin{array}{l}.047 \\
.005 \\
.0002 \\
.006 \\
.586 \\
.383 \\
.253 \\
.984 \\
.858 \\
1.117 \\
1.061\end{array}$ \\
\hline Constant & 51.067 & 64.153 & 68.578 & 64.979 & $110.472^{*}$ & 54.655 \\
\hline $\begin{array}{l}F \text {-statistic } \\
R^{2}\end{array}$ & $\begin{array}{c}2.34^{*} \\
.12\end{array}$ & & $\begin{array}{l}2.33 \\
.14\end{array}$ & & $\begin{array}{l}9.84 \\
.49\end{array}$ & \\
\hline$N$ & 150 & & 150 & & 131 & \\
\hline
\end{tabular}

Note: $+p \leq 0.10 ;{ }^{*} p \leq 0.05 ;{ }^{* *} p \leq 0.01$ (one-tailed tests). 